\title{
An experimental study of functional effect of low-ecological dam in channelized river
}

\author{
Wei Huang ${ }^{1, a^{*}}$, Tingyu $\mathrm{Li}^{2, \mathrm{~b}}$ and Wei Ma ${ }^{3, \mathrm{c}}$ \\ ${ }^{1}$ China Institute of Water Resources and Hydropower Research, Beijing, China \\ ${ }^{2}$ State Key Laboratory of Hydraulics and Mountain River Engineer, Sichuan University, China \\ ahwiwhr@qq.com, b1147605628@qq.com, 'mawei@iwhr.com
}

Keywords: habitat-enhanced structure, functional indicator, river health, river restoration.

Abstract. Increasing habitat-enhanced structures have been proposed to rehabilitate the channelized river, but the effects of these structures remained unclear. In this study, we carried out an experimental study to examine the effect of ecological low dam (ELD) on functional aspects of channelized river. The results showed that the ecological low dam can improve the decomposition rate of organic matter. Moreover, the ecological low dam can let the decomposition rate of leaves within health range. This finding was helpful for comprehensively understanding the effect of ELD on the functional aspects of river ecosystem and guild us to design ecological low dam optimally.

\section{Introduction}

Stream channelization is a widespread practice which has had large effects on instream biota, even has caused severe degradation of the natural ecosystems of rivers ${ }^{[1]}$. Recently, many kinds of habitat improvement structures or techniques have been proposed to improve the health of channelized river ecosystem. In order to use these structures for restoration of channelized rivers effectively, it is very necessary to know the environmental and ecological effect of these structures on the channelized river.

Ecological low dam (ELD) is one kind of structures, which is usually submerged in the river laterally and generates habitats similar to riffle-pool sequences. Some studies have studied its effect of restoration, for example, Shieds et al. ${ }^{[2]}$ studied the effect of ELD on fish species, and the results showed that the ELD can restore the river habitat complexity and enhance fish species. Chin et al. ${ }^{[3]}$ used the benthic macroinvertebrates as indicators to investigate the effect of ELD in an urban stream. Negishi and Richardson ${ }^{[4]}$ studied the organic matter and macorinvertebrate response to place of boulder clusters in a small stream, and find that ELD can enhance the amount of organic matter and macrinvertebrate. Harrison et al. ${ }^{[5]}$ examined the effect of instream rehabilitation structures on macroinvertebrates in lowland rivers, and showed that the instream rehabilitation structures can improve the macroinvertebrates. Holly et al. ${ }^{[6]}$ studied the response of periphyton and invertebrates to wood placement in similar channelized rivers near Pacific Coastal area, the findings showed that wood can serve as an important substrate for periphyton and invertebrates, and wood can support a unique community of invertebrates that are often underestimated. Obviously, previous studies showed that the effect of ELD structures have been received increasingly attention. However, these studies have mainly focused on the structural indicators such as invertebrate and periphyton biomass.

Recently, the functional indicators such as rates of ecosystem metabolism, organic matter decomposition, denitrification, nutrient spiralling, bacterial activity, and stable isotope analysis of food web components have been increasingly used to measure river ecosystem health or integrity ${ }^{[7]}$. Compared to structural indicators, much less effort has been devoted to evaluating their use in assessing the ecological integrity of streams ${ }^{[7-8]}$. Moreover, the functional effect of the ELD remains unclear.

In this study, we use an experimental flume to simulate the channelized river nearby and investigate the functional effect of the ELD. 


\section{Materials and method}

\section{Experiment design}

The studied river, which is called Kunyu River and located in the Haidian District of Beijing (Fig.1a), is a typical channelized river. The experiment setups are mainly consisted of one water supply and two flumes (Fig. 1b, Fig. 1c, Fig. 1d) with physical dimensions about $6 \mathrm{~m} \times 0.5 \mathrm{~m} \times 0.5 \mathrm{~m}$. One flume was with ELD while the other without ELD. The substrate of flume bed is from the Kunyu River nearby. Leaves of Populus trees, a typical species along river bank and one of the dominant tree species in the study area, were used to evaluate leaf litter decomposition in terms of leaf mass loss. Approximately $3.0( \pm 0.1) \mathrm{g}$ of air-dried leaves were placed into coarse-mesh leaf litter bags (mesh size: $0.5 \sim 1 \mathrm{~cm}$ aperture), allowing invertebrates to colonize and feed on the leaves. At each flume, three replicate bags were fastened onto rocks and incubated above the stream bed. The water was run continually for one month.

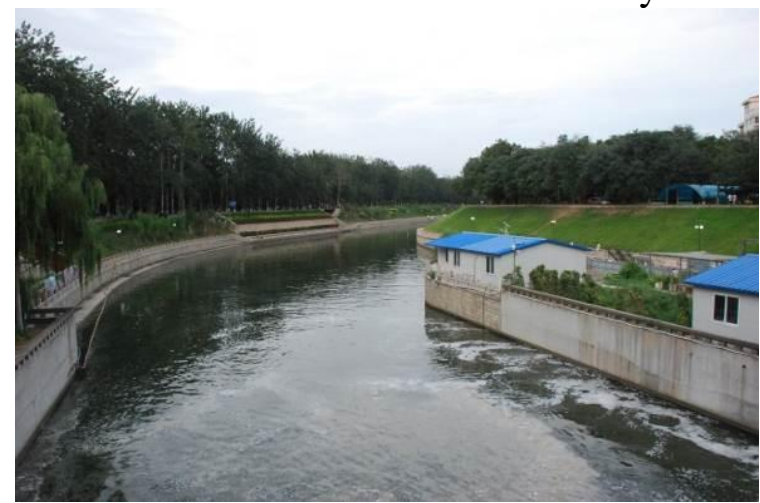

(a) The studied river

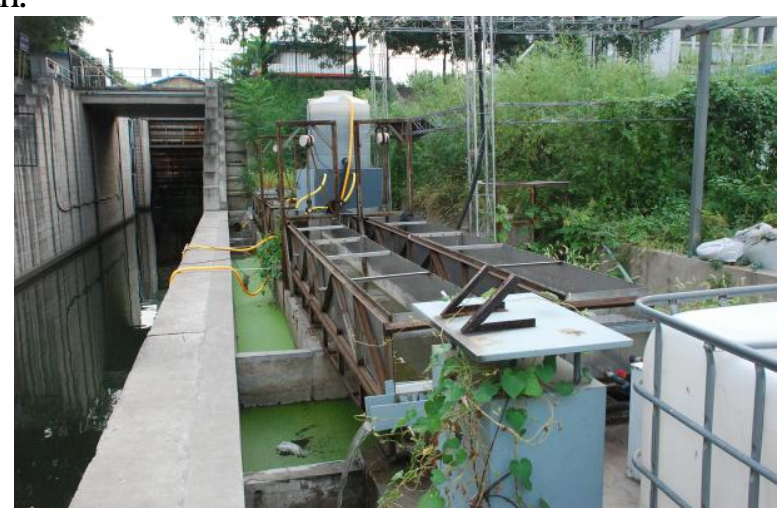

(b) The experiment setups

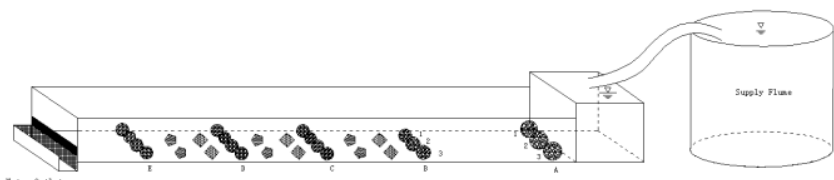

(c) Flume with ELD

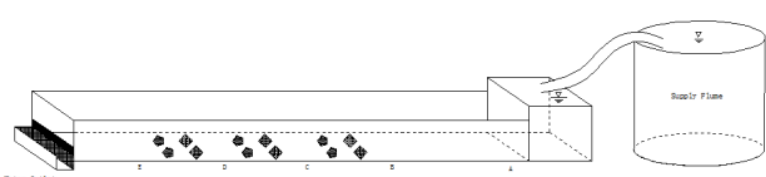

(d) Flume without ELD

Fig. 1 Study river and experiment setups

\section{Laboratory analysis}

Two replicate fine-mesh and coarse-mesh bags were retrieved from flumes one month after initial placement. The bags were placed in sealed plastic bags and returned to the laboratory. Leaves bags were gently cleaned under flowing tap water in the laboratory and then the leaves bags was oven-dried to constant weight $\left(65^{\circ} \mathrm{C}\right)$ and weighed.

Decomposition rates $\left(\right.$ day $^{-1}$ ) were calculated by fitting the remaining mass data (fraction Ln-transformed) into the negative exponential model

$$
M_{f}=M_{0} e^{-k t}
$$

where $M_{f}$ is the remaining AFDM, $M_{0}$ is the initial AFDM and $t$ is the incubation time in days. 


\section{Result and Discussion}

The weight of leaves in fine-mesh bags and coarse-mesh bags before incubation and after incubation were showed in the Table 1 . The mean decomposition of leaves in the fine-mesh bags are $2.16 \mathrm{~g}$ and $2.40 \mathrm{~g}$, respectively, in the flumes without ELD and with ELD. For leaves in the coarse-mesh bags, the mean decomposition are 2.20 and 2.57, respectively, in the flumes without ELD and with ELD.

Table 1 Leaves weight in fine-mesh bags and coarse-mesh bags before and after incubation (Unit: mg)

\begin{tabular}{|c|c|c|c|c|}
\hline \multirow{2}{*}{ Before } & \multicolumn{2}{|c|}{ Fine-mesh bags } & \multicolumn{2}{c|}{ Coarse-mesh bags } \\
\cline { 2 - 5 } & With ELD & Without ELD & With ELD & Without ELD \\
\hline \multirow{2}{*}{ After } & 3.76 & 4.12 & 3.97 & 3.62 \\
\cline { 2 - 5 } & 3.66 & 3.91 & 4.19 & 3.82 \\
\hline & 1.55 & 1.66 & 2.01 & 2.51 \\
\hline
\end{tabular}

With formula (1), the mean leaves decompostion rates in fine-mesh bags are 0.029 and 0.0304 , respectively, in the flume with ELD and without ELD. The mean leaves decompostion rates in coarse-mesh bags are 0.0258 and 0.0391 , respectively, in the flume with ELD and without ELD.

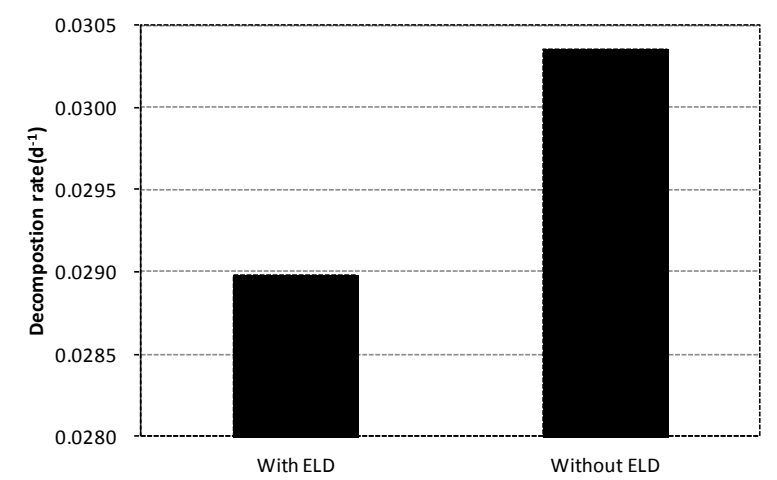

(a) Decomposition rate in fine-mesh bags

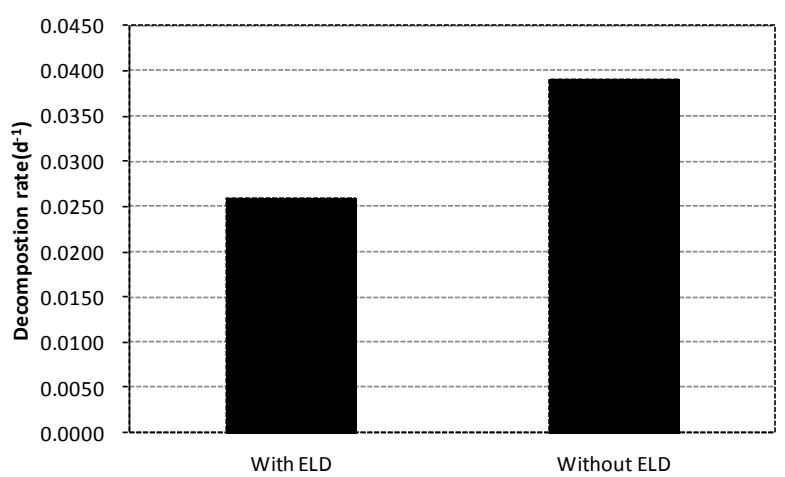

(b) Decomposition rate in coarse-mesh bags

Fig. 2 Decomposition rates of leaves in flumes with ELD and without ELD

From Fig.2, it was found that decomposition rates in fine-mesh bags differ from those in coarse-mesh bags, as well as in flumes with ELD and without ELD. Decomposition rate in fine-mesh bags was greater than that in coarse-mesh bags in the flume with ELD. By contrast, decomposition rate in coarse-mesh bags was greater than that in fine-mesh bags in the flume without ELD. The magnitude of leaf litter decomposition rates in our study was similar to the range reported for other studies ${ }^{[7-10]}$. 
Table 2 Frame work of the breakdown rate module for assessing functional stream integrity by means of litter breakdown assays.

\begin{tabular}{|c|c|c|c|}
\hline Method & Assessment parameter & Criterion & Score \\
\hline \multirow{3}{*}{ Comparison with reference } & \multirow{3}{*}{$\begin{array}{l}\text { Ratio of breakdown coefficients at } \\
\text { impacted }\left(k_{i}\right) \text { and reference }\left(k_{r}\right) \text { site }\end{array}$} & $K_{i}: K_{r}=0.75 \sim 1.33$ & 2 \\
\hline & & $K_{i}: K_{r}=0.5 \sim 0.75$ or $K_{i}: K_{r}=1.33 \sim 2.0$ & 1 \\
\hline & & $K_{i}: K_{r}<0.5$ or $>2.0$ & 0 \\
\hline \multirow{3}{*}{ Absolute value } & \multirow{3}{*}{ Breakdown coefficients at impacted $\left(k_{i}\right)$} & $K_{i}=0.01 \sim 0.03 / \mathrm{d}$ & 2 \\
\hline & & $K_{i}=0.0005 \sim 0.01 / \mathrm{d}$ or $0.03 \sim 0.05 / \mathrm{d}$ & 1 \\
\hline & & $K_{i}<0.0005 / \mathrm{d}$ or $K_{i}>0.05 / \mathrm{d}$ & 0 \\
\hline \multirow{3}{*}{ Absolute value of ratio } & \multirow{3}{*}{$\begin{array}{l}\text { Ratio of breakdown coefficient in coarse } \\
\left(k_{c}\right) \text { and fine }\left(k_{f}\right) \text { mesh bags }\end{array}$} & $K_{c}: K_{f}=1.2 \sim 1.5$ & 2 \\
\hline & & $K_{c}: K_{f}=1.5 \sim 2.0$ or $K_{c}: K_{f}<1.2$ & 1 \\
\hline & & $K_{c}: K_{f}>2.0$ & 0 \\
\hline
\end{tabular}

According to Gessner and Chauv ${ }^{[8]}$ in Table2, the scores of decompostion rates are 2 in both fine-mesh bags and coarse-mesh bags, while the scores of decompsotion rates are 1 in both fine-mesh bags and coarse-mesh bags. The results showed that the ELD can enhance the breakdown rate of organics matter in channelized river, namely, the ELD can improve the functional aspect of the channelized river in some degree.

It showed that there were differences in breakdown rate of leaves between flume with ELD and without ELD, the results agree with our hypothesis. It may be mainly attributed to differences in hydraulics setting because the physicochemical variables are almost the same, therefore, the decomposition rate is only related to the ELD in the flumes in the study. Like other sturctures such as engineered log jams, the ELD can form riffle-pool sequence in the flumes, and have a large effect on stream velocities, shear stress distributions, and drag forces. The ELD created hydraulic complexity in streams and thus improved the breakdown rate of organic matter $^{[11]}$.

\section{Conclusion}

In this paper, we carried out an experimental study on the functional effect of ELD, the results showed that the ELD can improve the breakdown rate of organic matter. Moreover, the breakdown rate of leaves in the flume with ELD are within the health range while the breakdown rate of leaves in the flume without flume lied in the sub-health range, it should that the ELD can improve the health of channelized river. However, further study should investigate the effect of forms of ELD on its restoration affect, which is useful for designing ELD optimally.

\section{Acknowledgements}

This research was supported by the Special Scientific Fund sponsored by the Chinese Institute of Water Resources and Hydropower Research (HJ1505).

\section{References}

[1]. Laasonen, P., T. Muotka, and I. Kivijarvi. 1998. Recovery of macroinvertebrate communities from stream habitat restoration. Aquatic Conservation: Marine and Freshwater Ecosystems 8:101-113.

[2]. Shields Jr, F. D., and Gippel, C. J. (1995). Prediction of effects of woody debris removal on flow resistance. Journal of Hydraulic Engineering, 121(4), 341-354.

[3]. Chin A, Gelwick F, Laurencio DE, Laurencio LR, Byars MS, and Scoggins M. Linking geomorphological and ecological responses in restored urban pool-riffle streams. Ecological Restoration, 2010(4).

[4]. Negishi JN, and Richardson JS. Responses of organic matter and macroinvertebrates to placements of boulder clusters in a small stream of southwestern British Columbia, Canada. Canadian Journal of Fisheries and Aquatic Sciences, 2003(60): 247-258. 
[5]. Harrison SSC, Pretty JL, Shepherd D, Hildrew AG, Smith C and Hey RD. The effect of instream rehabilitation structures on macroinvertebrates in lowland rivers. Journal of Applied Ecology, 2004(4)1,1140-1154.

[6]. Brookes A. Restoration and enhancement of engineered river channels: some European Experiences. Regulated Rivers: Research and Management,1990(5): 45-56.

[7]. Young, R. G., Matthaei, C. D., and Townsend, C. R. (2008). Organic matter breakdown and ecosystem metabolism: functional indicators for assessing river ecosystem health. Journal of the North American Benthological Society, 27(3), 605-625.

[8]. Gessner, M. O., and E. Chauvet. 2002. A case for using litter breakdown to assess functional stream integrity. Ecological Applications 12:498-510.

[9]. Castela J., Ferreira V. and Grac a M.A.S. (2008). Evaluation of stream ecological integrity using litter decomposition and benthic invertebrates. Environmental Pollution, 153, 440-449.

[10]. Gulis V. and Suberkropp K. (2003) Effect of inorganic nutrients on relative contributions of fungi and bacteria to carbon flow from submerged decomposing leaf litter. Microbial Ecology, 45, 11-19.

[11]. Manners, R. B., Doyle, M. W., and Small, M. J. (2007). Structure and hydraulics of natural woody debris jams. Water Resources Research, 43(6). 